\title{
Subdural hematoma in infants: can it occur spontaneously? Data from a prospective series and critical review of the literature by Vinchon et al
}

\author{
Horace B. Gardner
}

Received: 5 July 2010 / Accepted: 7 July 2010 /Published online: 20 July 2010

(C) Springer-Verlag 2010

Dear Editor,

Now that Vinchon [1] has validated Piatt's [2] observation that the diagnosis of abuse is unsafe in infants with preexisting enlarged cerebrospinal fluid spaces, the entire abuse literature needs revision to remove all such cases from the abuse category to the non-abuse or at least the undetermined categories. Rather than comparing "spontaneous" to "abuse" cases, Vinchon apparently has sufficient clinical material to compare those cases with either rapid head growth (crossing two percentile lines) or increased space between the brain and skull (McNeely [3] used $5 \mathrm{~mm}$ ) on presentation to those without. This may be the more informative comparison.

\section{References}

1. Vinchon M, Delestret I, DeFoort-Dhellemmes S, Desurmont M, Noule N (2010) Subdural hematoma in infants: can it occur spontaneously? Data from a prospective series and critical review of the literature. Childs Nerv Syst (in press)

2. Piatt JH Jr (1999) A pitfall in the diagnosis of child abuse: external hydrocephalus, subdural hematoma, and retinal hemorrhages. Neurosurg Focus 7:e4

3. McNeely PD, Atkinson JD, Saigal G, O'Gorman AM, Farmer JP (2006) Subdural hematomas in infants with benign enlargement of the subarachnoid spaces are not pathognomonic for child abuse. Am J Neuroradiol 27:17251728
H. B. Gardner $(\bowtie)$

318 Oklahoma Road,

Manitou Springs, CO 80829, USA

e-mail: horacebgardner@yahoo.com 